\title{
Quantificaçáo de Corpos de Neurônios em Camundongos Submetidos ao Uso de Esteróides Anabolizantes
}

\author{
Quantitative In the Number of Bodies Neurons In Mice Submitted by the Use of Anabolic Steroids
}

\author{
Bruno Damiāo ${ }^{1}$, Guilherme Gonzales de Souza², Denismar Alves \\ Nogueira3 ${ }^{3}$ Wagner Costa Rossi Junior 4 , Geraldo José Medeiros Fernandes 5 , \\ Alessandra Esteves ${ }^{6}$
}

\begin{abstract}
RESUMO
Objetivo. Verificar possíveis alteraçóes quantitativas de corpos de neurônios, no córtex cerebral, causadas pelo uso de esteróides anabolizantes. Método. Foram utilizados trinta camundongos divididos em 3 grupos (grupo 1 - Deca Durabolin ${ }^{\oplus}$; grupo 2- Potenay ; grupo 3- Salina) tratados uma vez na semana e submetidos à natação três vezes na semana, tendo o tratamento a duraçáo total de um mês. Após a eutanásia os encéfalos foram retirados e foram preparados segundo técnica histológica convencional e corados com violeta cresil, através da análise morfométrica foram buscados os dados comparativos. Resultados. Os resultados obtidos revelaram que houve uma diminuição significativa do número de corpos de neurônios nos animais tratados $(\mathrm{P}<0,01)$ quando comparados com o grupo controle, porém não foi significativo $(\mathrm{P}>0,05)$ quando comparados os dois sexos. Os animais do grupo Potenay ${ }^{\oplus}$ apresentaram 23,36 corpos de neurônios enquanto que os animais do grupo Deca-durabolin ${ }^{\circledR}$ apresentaram 23,40 corpos de neurônios, os valores médios de corpos de neurônios foram iguais e inferiores aos observados para o grupo controle que foi de 31,70. Conclusáo. Concluímos que a densidade de corpos de neurônios no córtex cerebral mostra uma diminuição significativa nos camundongos submetidos ao tratamento com esteróides anabolizantes em relação ao grupo controle.
\end{abstract}

Unitermos. Anabolizantes, Corpos de Neurônios, Esteróide, Camundongos.

Citaçáo. Damiāo B, Souza GG, Nogueira DA, Rossi Junior WC, Fernandes GJM, Esteves A. Quantificação de Corpos de Neurônios em Camundongos Submetidos ao Uso de Esteróides Anabolizantes.

Suporte financeiro: Fapemig.

Trabalho realizado no Departamento de Anatomia da Universidade Federal de Alfenas, Alfenas-MG, Brasil.

1.Biomédico graduando pela Unifal-MG, Alfenas-MG, Brasil.

2.Biólogo graduando pela Unifal-MG, Alfenas-MG, Brasil.

3.Zootecnista, Doutor e Docente da Unifal-MG, Alfenas-MG, Brasil.

4.Cirurgião dentista, Doutor Docente da Unifal-MG, Alfenas-MG, Brasil.

5.Médico, Doutor Docente da Unifal-MG, Alfenas-MG, Brasil.

6.Médica Veterinária, Doutora Docente da Unifal-MG, Alfenas-MG, Brasil.

\begin{abstract}
Objective. Investigate quantitative changes in cerebral cortex neurons bodies caused by the use of anabolic steroids. Method. Thirty mice were used, which received treatment with steroids (group 1- Deca Durabolin ; group 2- Potenay'; group 3- Saline) once a week and submitted to swimming three times a week, taking total treatment duration one month. After euthanasia, the brains were removed, fixed and histological processed and cresyl violet was used for staining. The slices were analyzed by light microscope and software to count the neurons bodies. Results. The results shows that there was a significant decrease of neurons bodies number in treated groups $(\mathrm{P}<0.01)$ when compared with the control group, but was not significant $(\mathrm{P}>0.05)$ when both genders were compared. In Potenay ${ }^{\bullet}$ group, the animals showed 23.36 neurons bodies while the animals in Deca-durabolin ${ }^{\oplus}$ group had 23.40. The average values of neuron bodies were equal and lower than of control group, which was 31.70. Conclusion. The neuronal bodies density in cerebral cortex decreased significantly in mice undergoing treatment with steroids in relation to control group.
\end{abstract}

Keywords. Anabolic, Neuron Bodies, Steroid, Mices.

Citation. Damião B, Souza GG, Nogueira DA, Rossi Junior WC, Fernandes GJM, Esteves A. Quantitative In the Number of Bodies Neurons In Mice Submitted by the Use of Anabolic Steroids.

Endereço para correspondência: Profa. Dra. Alessandra Esteves

Universidade Federal de Alfenas Departamento de Anatomia do Instituto de Ciências Biomédicas Rua Gabriel Monteiro da Silva, 700, Centro CEP 37130-000, Alfenas-MG, Brasil. Fone: +35 32991302

E-mail: aesteves@unifal-mg.edu.br

Original Recebido em: 15/03/11 Aceito em: 09/08/11 Conflito de interesses: não 


\section{INTRODUÇÃO}

Os esteróides anabolizantes são um grupo de compostos naturais e sintéticos formados a partir da testosterona ou de um de seus derivados ${ }^{1}$.

A testosterona foi pela primeira vez sintetizada em 1935 e, desde então, os andrógenos tornaram-se disponíveis para utilizaçôes com fins terapêuticos e experimentais. Os esteróides androgênicos referem-se aos hormônios sexuais masculinos, podendo ser definidos como qualquer substância que produz especificamente o crescimento das gônadas masculinas ${ }^{2}$.

Inicialmente, houve pouco interesse por parte dos pesquisadores, na determinação dos efeitos de tais compostos $^{3}$.

A primeira utilização dos esteróides anabolizantes com o objetivo de melhorar o desempenho de atletas em competição ocorreu em 1954, quando atletas russos que fizeram uso de tais substâncias obtiveram performances altamente satisfatórias em uma competição de levantamento de peso ${ }^{4}$.

Mesmo proibido o uso dos esteróides anabolizantes a partir de 1989, o uso de tais substâncias ainda faz parte do meio desportivo, competitivo ou não, porque muitos acreditam que a eles também se aplica a lei Darwiniana: somente os mais preparados fisicamente alcançam os níveis mais altos de participação 5 .

Tendo em vista a semelhança estrutural e comportamental com o ser humano decidimos então trabalhar com o camundongo ${ }^{6}$.

Por motivos como estes, e por cada vez mais jovens estarem utilizando tais substâncias para melhorarem seu desempenho físico ou apenas por motivos estéticos, que os esteróides anabolizantes devem ser continuamente estudados, buscando conhecer mais e mais seus riscos e as consequências do uso indiscriminado e sem acompanhamento médico, os quais são dependentes da dose e do tempo pelo qual são utilizadas e os seus possíveis benefícios.

\section{MÉTODO}

\section{Amostra}

Para verificar as possíveis alterações neuronais com o uso de esteróides anabolizantes foram utilizados $30 \mathrm{ca}$ mundongos, divididos em 3 grupos de 10 animais cada, sendo 15 machos e 15 fêmeas. Os grupos foram assim divididos: grupo 01 contendo 05 machos e 05 fêmeas tratados com Potenay ${ }^{\circledR}$ na dosagem de $0,5 \mathrm{mg}$ para cada $100 \mathrm{gr}$ de peso vivo; grupo 02- 05 machos e 05 fêmeas tratados com Deca-durabolin ${ }^{\bullet}$ na dosagem de $0,5 \mathrm{mg}$ para cada $100 \mathrm{gr}$ de peso vivo e grupo 03- 05 machos e 05 fêmeas (grupo controle) tratados com solução fisiológica $(10 \mathrm{mg} / \mathrm{kg})$. Foi administrada uma dose semanal durante 4 semanas.

O projeto de pesquisa foi encaminhado à apreciação do Comitê de Ética em Pesquisa e ao Comitê de Ética na Experimentação Animal - CEEA da Universidade Federal de Alfenas - UNIFAL-MG, registro no 224/2009. Após parecer favorável, iniciou-se o experimento. Este foi realizado nos Laboratórios de Anatomia e Histologia da Universidade Federal de Alfenas - Unifal-MG.

\section{Procedimento}

Os animais, seis horas após receberem as doses dos anabolizantes esteróides ${ }^{7}$, foram submetidos à natação por 30 minutos. Uma vez por semana os animais eram pesados para observância da massa corporal (Tabela 1).

Após a eutanásia por inalação de éter etílico, as cabeças foram abertas e os encéfalos retirados inteiramente para compilação dos dados, referentes aos pesos e medidas do órgão. Estes foram armazenados em recipientes de vidro contendo formaldeído a $4 \%$ e entâo identificados.

Os encéfalos permaneceram imersos nesta solução fixadora por três semanas ${ }^{8,9}$. Em cada encéfalo foram retiradas amostras homotípicas da região média do cérebro em cortes sagitais ${ }^{10}$ para que pudéssemos avaliar as áreas então estabelecidas para este estudo ${ }^{11}$.

Os fragmentos foram processados seguindo-se a sequência padronizada nos procedimentos histológicos convencionais: desidratação em álcool, diafanização em xilol e inclusão em parafina ${ }^{12}$. Cada região foi emblocada e cortada com espessura de $5 \mathrm{~mm}$ em micrótomo Leica 2165 e coradas com violeta cresil para facilitar a visualização dos Corpúsculos de Nissl dos corpos de neurônios e assim possibilitar marcar fortemente e individualmente cada célula para posterior contagem. Para a análise quantitativa, foram selecionados cinco cortes por região, seguindo-se então a mensuração manual com auxílio de um retículo desenhado e fixado no monitor do computador 
Tabela 1

Resumo da análise da variância para ganho de peso dos animais em gramas durante as 4 semanas de tratamento

\begin{tabular}{|c|c|c|c|c|c|}
\hline & $1^{\text {a }}$ Sem & $2^{\text {a }}$ Sem & $3^{\mathrm{a} S e m}$ & $4^{\mathrm{a} S e m}$ & $\mathbf{p}$ \\
\hline \multicolumn{6}{|c|}{ Potenay $^{\circledR}$} \\
\hline Machos & 32,0 & 33,6 & 35,2 & 36,4 & ${ }^{* *} 0,01$ \\
\hline Fêmeas & 26,4 & 27,6 & 28,8 & 29,8 & ns \\
\hline \multicolumn{6}{|c|}{ Deca Durabolin ${ }^{\circledR}$} \\
\hline Machos & 31,4 & 33,4 & 35,2 & 36,6 & ${ }^{* *} 0,01$ \\
\hline Fêmeas & 27,6 & 28,6 & 31,0 & 31,4 & ns \\
\hline \multicolumn{6}{|c|}{ Controle } \\
\hline Machos & 31,6 & 32,2 & 33,6 & 34,4 & ns \\
\hline Fêmeas & 30,6 & 30,8 & 32,0 & 33,0 & ns \\
\hline
\end{tabular}

ns=não significante

para quantificação de pontos inseridos somente dentro dos quadrantes, excluindo pontos nas linhas do retículo. Em cada corte foram contados cinco campos distintos, obtendo-se deles uma média; das cinco médias obteve-se uma média final para análise estatística ${ }^{9,13,14}$.

Foram realizadas análises descritivas do número médio de corpos de neurônios, visando estabelecer o padrâo característico de cada um dos animais, bem como foi efetuada a verificação das pressuposições comumente utilizadas em análises de dados experimentais. As análises descritivas foram realizadas por meio de procedimento PROC MEANS do programa Statistical Analysis Systems.

Para avaliação dos números médios de corpos de neurônios, segundo as diferenças sexo e tratamentos (grupos estudados) utilizou-se a análise de variância. Quando verificado o efeito significativo $(\mathrm{P}<0,01)$ na análise de variância entre os grupos comparativos para as diferentes variáveis estudadas, utilizou-se o Teste de Tukey para discriminar as diferenças e/ou igualdades entre as médias avaliadas.

\section{RESULTADOS}

Observou-se um ganho significante de peso nos machos, na última semana, tratados com Potenay ${ }^{\circ}(36,4$ gramas de peso vivo) em relação ao grupo controle $(34,4$ gramas de peso vivo) e ao grupo tratado com Deca-durabolin $^{\oplus}$ (31,4 gramas de peso vivo) (Tabela 1). Enquanto que nas fêmeas o resultado obtido foi inverso ao encontrado nos machos. Com o uso de esteróides anabolizantes as fêmeas obtiveram um peso menor que as do grupo controle, no grupo Potenay ${ }^{\oplus}$ o peso vivo dos animais foi de 29,8 gramas; o grupo submetido ao tratamento com Deca-durabolin ${ }^{\oplus}$ o peso foi de 31,4 gramas já o grupo controle o peso foi de 33 gramas.

Observa-se que a fonte de variação tratamento (grupos tratados) foi significante $(\mathrm{P}<0,01)$ quando comparados entre si, porém não foi significante $(\mathrm{P}>0,01)$ dentro dos tratamentos avaliando sexos e também não foi significante quando comparados os sexos (Tabela 2).

As estimativas de médias dos corpos de neurônios em cada grupo estudado encontram-se na Tabela 3. O grupo Potenayâ apresentou 23,36 corpos de neurônios e o grupo Deca-durabolinâ, 23,40 corpos de neurônios mostrando que os valores médios foi inferior aos observados para o grupo controle de 31,70 corpos de neurônios $(\mathrm{P}<0,01)$. Estes valores mostram uma diminuição de $30 \%$ na densidade média de corpos de neurônios dos animais submetidos ao tratamento com esteróides anabolizantes.

\section{DISCUSSÃO}

Poucos foram os estudos até o presente momento da relação do uso de anabolizantes esteróides e diminuição no número de corpos de neurônios. A grande porcentagem de trabalhos publicados está associada aos graves efeitos colaterais psicogênicos que altas doses de anabólicos esteróides incluindo comportamento agressivo e violento e dependência química que tais substâncias provocam. Também são comuns em usuários de tais substâncias os transtornos psiquiátricos ${ }^{15-17}$. Estes resultados obtidos por tais autores nos mostra que pode existir uma 
Tabela 2

Resumo da análise da variância para o número médio dos corpos de neurônios avaliados

\begin{tabular}{ccccc}
\hline Fontes de Variaçáo & GL & QM & $\mathbf{F}$ & $\mathbf{p}$ \\
\hline TRAT & 2 & 230.93 & 831.589 & ${ }^{* *} 0,01$ \\
SEXO & 1 & 0.116151 & 0.418 & ns \\
TRAT*SEXO & 2 & 0.275741 & 0.993 & ns \\
Erro & 24 & 0.277696 & & \\
\hline
\end{tabular}

ns=não significante; $\mathrm{GL}=$ grau de liberdade; $\mathrm{QM}=$ quadrado médio; $\mathrm{F}=$ fator de variância

Tabela 3

Estimativas de médias das densidades de corpos de neurônios no córtex cerebral dentro de cada grupo avaliado

\begin{tabular}{ccc}
\hline Tratamentos & Médias & Resultados* $^{*}$ \\
\hline Potenay $^{\circledR}$ & 23.36 & $\mathrm{a}$ \\
Deca Durabolin $^{\circledast}$ & 23.40 & $\mathrm{a}$ \\
Controle $^{*}$ & 31.70 & $\mathrm{~b}$ \\
\hline
\end{tabular}

Médias seguidas por uma mesma letra, não diferem entre si ao nível de $1 \%$ de probabilidade pelo Teste Tukey $(\mathrm{P}<0,01)$

relação da maior frequência de brigas e distúrbios comportamentais entre as fêmeas tratadas, em relação ao observado no grupo controle neste recente trabalho.

O uso abusivo de esteróides anabolizantes leva a problemas no sistema cardiovascular, reprodutor e ainda distúrbios metabólicos ${ }^{18}$. Este trabalho nos leva também a sugerir que tais substâncias podem levar a problemas graves a nível tecidual e celular no córtex cerebral.

O uso de anabolizantes esteróides aumenta as chances de morte neuronal em regióes corticais no cérebro de camundongos ${ }^{6}$. Os resultados obtidos neste trabalho estão de acordo com a literatura consultada, mostrando uma diminuição significativa no número de corpos de neurônios em diferentes áreas corticais em camundongos.

A influência de esteróides anabolizantes em ratas ovariectomizadas mostrou uma diferença estatística significativa entre as ratas tratadas em relação ao grupo controle tanto no volume do núcleo neuronal como também no número de células quantificadas, mostrando ser maior nas ratas que foram submetidas ao processo cirúrgico e logo após tratadas com estradiol+progesterona ${ }^{19}$. Nosso estudo demonstrou uma diminuição no número de corpos neuronais tanto em machos como em fêmeas. Estes resultados apresentados pelos autores acima citados e o presente estudo são de certa forma controversos justamente pelo tipo de hormônio e metodologia empregados que podem mostrar resultados bem diferentes.

\section{CONCLUSÃO}

Portanto os resultados permitem concluir que a densidade de corpos de neurônios no córtex cerebral diminuiu significativamente nos camundongos submetidos ao tratamento com esteróides anabolizantes em relação ao grupo controle, isso nos leva a sugerir que o uso inadequado e sem orientação médica de anabolizantes esteróides pode levar a degeneraçóes nervosas e perda das atividades cerebrais e cognitivas.

\section{REFERÊNCIAS}

1.Cunha TS. Efeito do esteróide anabólico androgênico nandrolona sobre o metabolismo do glicogênio em ratos sedentários e treinados (Dissertaçáo de Mestrado). Piracicaba: UNICAMP, 2004, 89p.

2.Handa JR, Price RH. Androgen Action. In: FINK, G. Encyclopedia of stress. New York: Academic Press, 2000,1:183-8.

3.Samuels LT, Henschel AF, Keys A. Inflence of methyl testosterone on muscular work and creatine metabolism in normal young men. J Clin Endocrinol Metab 1942;2:649-54

http://dx.doi.org/10.1210/jcem-2-11-649

4.Assis WS. Efeitos da natação associada ao uso de dois esteróides anabolizantes (estanozolol e decanoato de nandrolona) sobre as fibras musculares oxidativas e glicolíticas do músculo gastrocnêmio de ratos (Dissertação de Mestrado). Rio Claro: UNESP 2002, 181p.

5.Norton K, Olds T. Morphological evolution of athletes over the 20th century: causes and consequences. Sports Med 2001;31:763-83.

http://dx.doi.org/10.2165/00007256-200131110-00001

6. Orlando R, Caruso A, Molinaro G, Motolese M, Matrisciano F, Togna G, et al. Nanomolar concentrations of anabolic-androgenic steroids amplify excitotoxic neuronal death in mixed mouse cortical cultures. Brain Res 2007;24:21-9. http://dx.doi.org/10.1016/j.brainres.2007.06.047

7.Vieira RP. Estudo do decanoato de nandrolona sobre o fígado de ratos Wistar (Dissertaçăo de Mestrado). São Paulo: Universidade do Vale do Paraíba, 2003, 63p.

8.Rabinowicz T, Dean DE, Petetot JMC, Myers GMC. Gender differences in the human cerebral cortex: more neurons in males; more processes in female. J Child Neurol 1999;14:98-107.

http://dx.doi.org/10.1177/088307389901400207

9.Rabinowicz T, Petetot JM, Gartside PS, Sheyn D, Sheyn T, Courten-Meyrs GM. Structure of the cerebral cortex in men and women. J Neuropathol Exp Neurol 2002;61:46-67.

10.Brown MW, Aggleton JP. Recognition memory: What are the roles of the perirhinal córtex and hippocampus? Neuroscience 2001;2:51-61.

11.Strien NM, Cappaert NLM, Witter MP. The anatomy of memory: na in- 
teractive overview of the parahippocampal - hippocampal network. Neuroscience 2009;10:272-82.

12.Tolosa EMC, Rodrigues CJ, Behmer AO, Freitas AGN. Manual de técnicas para histologia normal e patológica. São Paulo: Manole, 2003, 331p.

13.Michon J J, Li Zl, Shioura N, Anderson RJ, Tso MOM. A comparative study of methods of photoreceptor morphometry. Invest Ophthalmol Vis Sci 1991;32(2):280-4.

14.Avrushchenko MS. Morphometric study of purkinje cells in the dog cerebellar córtex. Bull Exp Biol Med 1981;92(9):363-6.

15.Currigann B. Anabolic steroids and the mind. Med J Aust 1996;165:222-6. 16.Grimes JM, Ricci LA, Melloni Junior RH. Plasticity in anterior hypothalamic vasopressin correlates with aggression during anabolic-androgenic steroid withdrawal in hamsters. Behav Neurosci 2006;120:115-24. http://dx.doi.org/10.1037/0735-7044.120.1.115

17.Cunningham RL, Claiborne BJ, Mcginnis MY. Pubertal exposure to anabolic androgenic steroids increases spine densities on neurons in the limbic system of male rats. Neuroscience 2007;150(3):609-15.

http://dx.doi.org/10.1016/j.neuroscience.2007.09.038

18. Karila T. Adverse effects os anabolic androgenic steroids on the cardiovascular, metabolic and reproductive systems of anabolic substance abusers (.Dissertation). Cidade: University of Helsinki, 2003, 70 f.

19.Castilhos J, Hermel EES, Rasia-Filho AA, Achaval M. Influence of substitutive ovarian steroids in the nuclear and cell body volumes of neurons in the posterodorsal medial amygdala of adult ovariectomized female rats. Neurosci Lett 2010;469(1):19-23.

http://dx.doi.org/10.1016/j.neulet.2009.11.036 